\title{
Malignant Degeneration into Chondrosarcoma of Multiple Exostosis Dis- ease: The First Senegalese Case Report
}

Moustapha Niasse $^{1 *}$, Baïdy Sy Kane ${ }^{2}$, Abdou Majib Gaye ${ }^{3}$, El Hadii Modou Ndiaye ${ }^{2}$, Ibrahima Faye ${ }^{4}$, Maïmouna Sow ${ }^{2}$, Tafsir Ngary Ka², Alioune Badara Diallo², Atoumane Faye², Saïdou Diallo'

Department of Rheumatology, Aristide Le Dantec Teaching Hospital; Cheikh Anta DIOP University of Dakar, Senegal

${ }^{2}$ Department of Internal Medicine, Aristide Le Dantec Teaching Hospital; Cheikh Anta DIOP University of Dakar, Senegal

${ }^{3}$ Department of Anatomy and pathology, Aristide Le Dantec Teaching Hospital; Cheikh Anta DIOP University of Dakar, Senegal

${ }^{4}$ Department of Radiology, Aristide Le Dantec Teaching Hospital; Cheikh Anta DIOP University of Dakar, Senegal

Article Info

\section{Article Notes}

Received: September 22, 2019

Accepted: November 06, 2019

\section{*Correspondence:}

Dr. Moustapha Niasse, Department of Rheumatology, Aristide Le Dantec Teaching Hospital; Cheikh Anta DIOP University of Dakar, Senegal;

Email: moustaphaniasse4@yahoo.fr

(c) 2019 Niasse M. This article is distributed under the terms of the Creative Commons Attribution 4.0 International License.

\section{Keywords:}

Multiple exostosis disease

Malignant degeneration

Chondrosarcoma

Sub-Saharan Africa

\section{Introduction}

Multipleexostosis disease (MED)isahereditarybenignbonetumor with autosomal dominant transmission ${ }^{1,2,3}$. It is the consequence of a mutation of tumor suppressor genes, EXT1 (chromosome 8q23-q24) ${ }^{4,5}$, EXT2 (chromosome 11p11-p13) ${ }^{6}$ and possibly EXT3 (chromosome 19$)^{2}$. MED is a rare disease and his prevalence has been estimated at $1 / 50000$ in the western population ${ }^{7,8}$. Malignant degeneration is the most serious complication; however, it is rare and found in $2 \%$ to $5 \%$ of cases $^{9,10}$. We report the first Senegalese observation of malignant degeneration into chondrosarcoma of multiple exostosis disease.

\section{Observation}

A 43-year-old man had been followed since March 2016 in our department for a family form of MED (MED was also found in his daughter). The disease has been evolved since the age of 2 years. Exostosis was found in metaphysis's long bones and in the left iliac bone (Figure 1). The patient had a Bessel Hagen deformity in his left forearm (Figure 1). He had consulted after 40 years of evolution

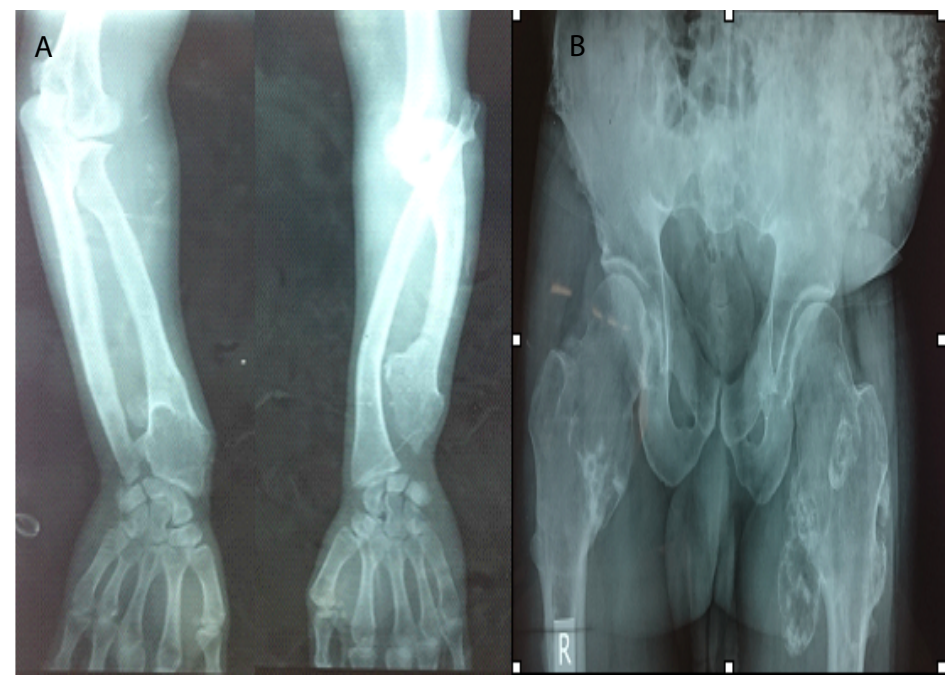

Figure 1: Before surgery: exostosis of the metaphysis of the long bones ( $A$ $B)$ and the left iliac bone (B). Bessel Hagen disease : arched deformation of the ulna and dysharmony of length between the ulna and the radius (A). 
for pain of osteochondroma of the left iliac bone. The surgical resection of the mass was performed. Histological examination showed compact cartilage and bone tissue casings. The bone tissue consisted of regular spans around the Havers canals. The cartilage tissue contained medullary tissue with fibrous reworking. There was no suspicious sign of malignancy.

The evolution was marked after 2 years by a recurrence of the mass with signs of local compression (a large left lower limb without venous thrombosis on Doppler ultrasound with neuropathic pain in the form of electric shocks and burning, resistant to Paracetamol and Tramadol) (Figure 2).

Biological explorations showed an inflammatory syndrome with a sedimentation rate at $95 \mathrm{~mm}$ in the first hour, a C-reactive protein at $133.64 \mathrm{mg} / \mathrm{l}$ and a microcytic anemia at $11 \mathrm{~g} / \mathrm{dl}$. Serum calcium was $85.25 \mathrm{mg} / \mathrm{l}$ and serum creatinine was $7.9 \mathrm{mg} / \mathrm{l}$.

The abdominal and pelvic CT scan followed by magnetic resonance imaging showed a large tumor formation centered on the left iliac bone with an abdominal development portion and a parietal development portion (figure 2). It was an infiltration of the gluteal muscles and the left psoas. The left kidney was pushed forward and bladder, rectum, sigmoid to the right.

Histological examination of the mass biopsy piece showed a malignant degeneration to grade I chondrosarcoma (Figure 3). The technical platform did not allow an immunohistochemical examination of the biopsy piece, and genetic tests.

The evolution was marked by the occurrence of respiratory failure death in a context of cachexia and pulmonary metastasis (Figure 4). The patient's cachectic state did not allow a biopsy of the metastastic lesions to be performed.

\section{Discussion}

We reported the case of malignant degeneration of multiple exostosis disease. This observation has an epidemiological also diagnostic and prognostic interest.

The prevalence of malignant transformation of MED has been subject to variations according to the literature ${ }^{8,11}$. In a Western multicenter study including 742 patients followed for multiple exostosis disease, it was $2.7 \%{ }^{11}$. The most recent studies have estimated this prevalence between $2 \%$ to $5 \%{ }^{12}$. In Africa, this prevalence has not been estimated; however, in North Africa, Ahmed AR et al reported a series of 107 cases of chondrosarcomas secondary to multiple exostosis disease in Egypt ${ }^{13}$. In Morocco, Shahdi $\mathrm{H}$ et al described 01 case of this condition ${ }^{14}$. In Sub-Sahara, some observations have been reported in South Africa by Solomon $\mathrm{L}(3 \text { cases })^{15}$ and Vlok S.C.S et al $(1 \text { case })^{16}$. Malignant degeneration is thus an extremely rare complication of the

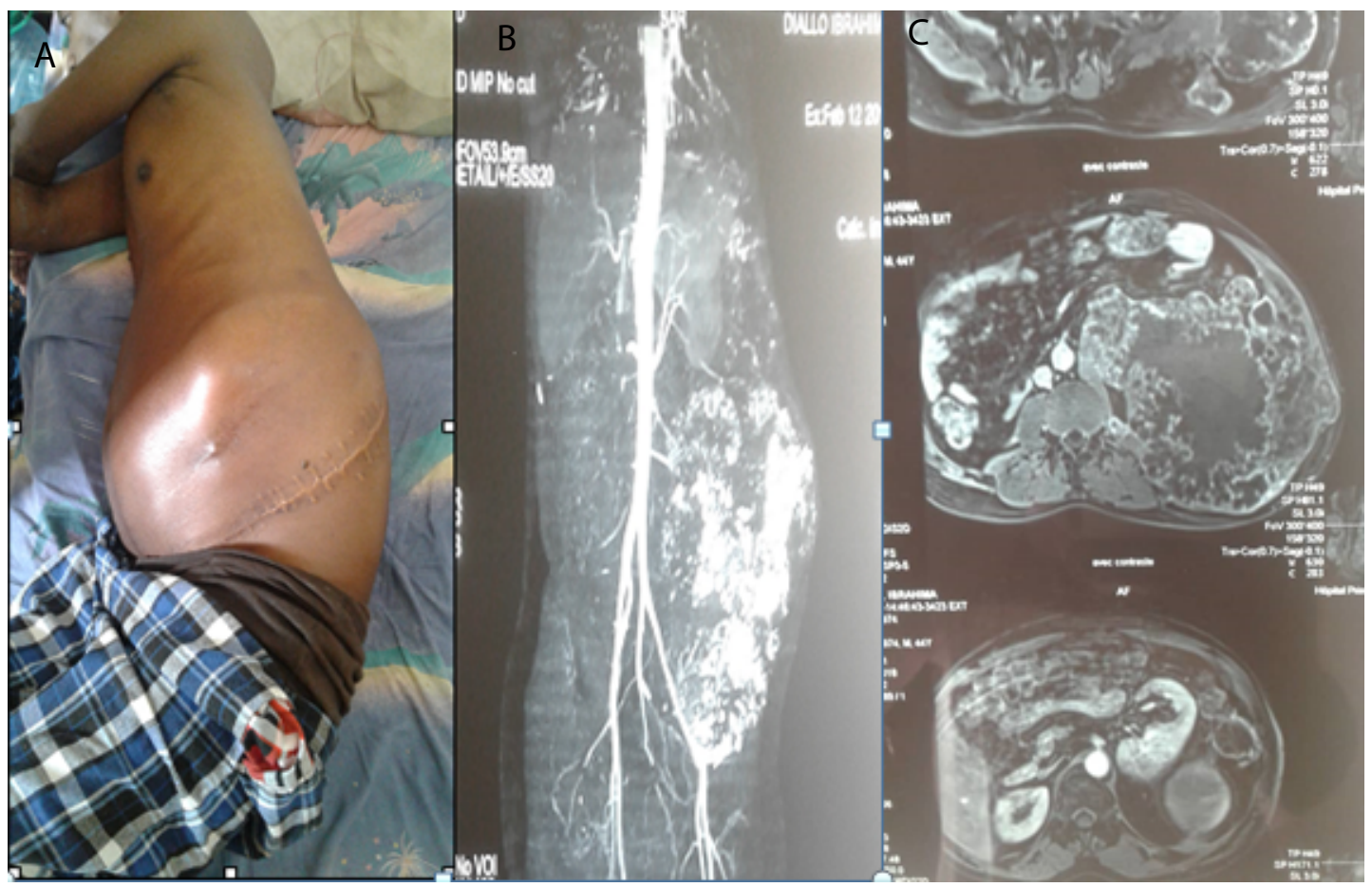

Figure 2 : Two years after surgery: recurrence of the tumor with a mass centered in the left iliac bone perceptible on clinical examination (A). It invades the surrounding organs on the CT scanner (B) and magnetic resonance imaging (C). 


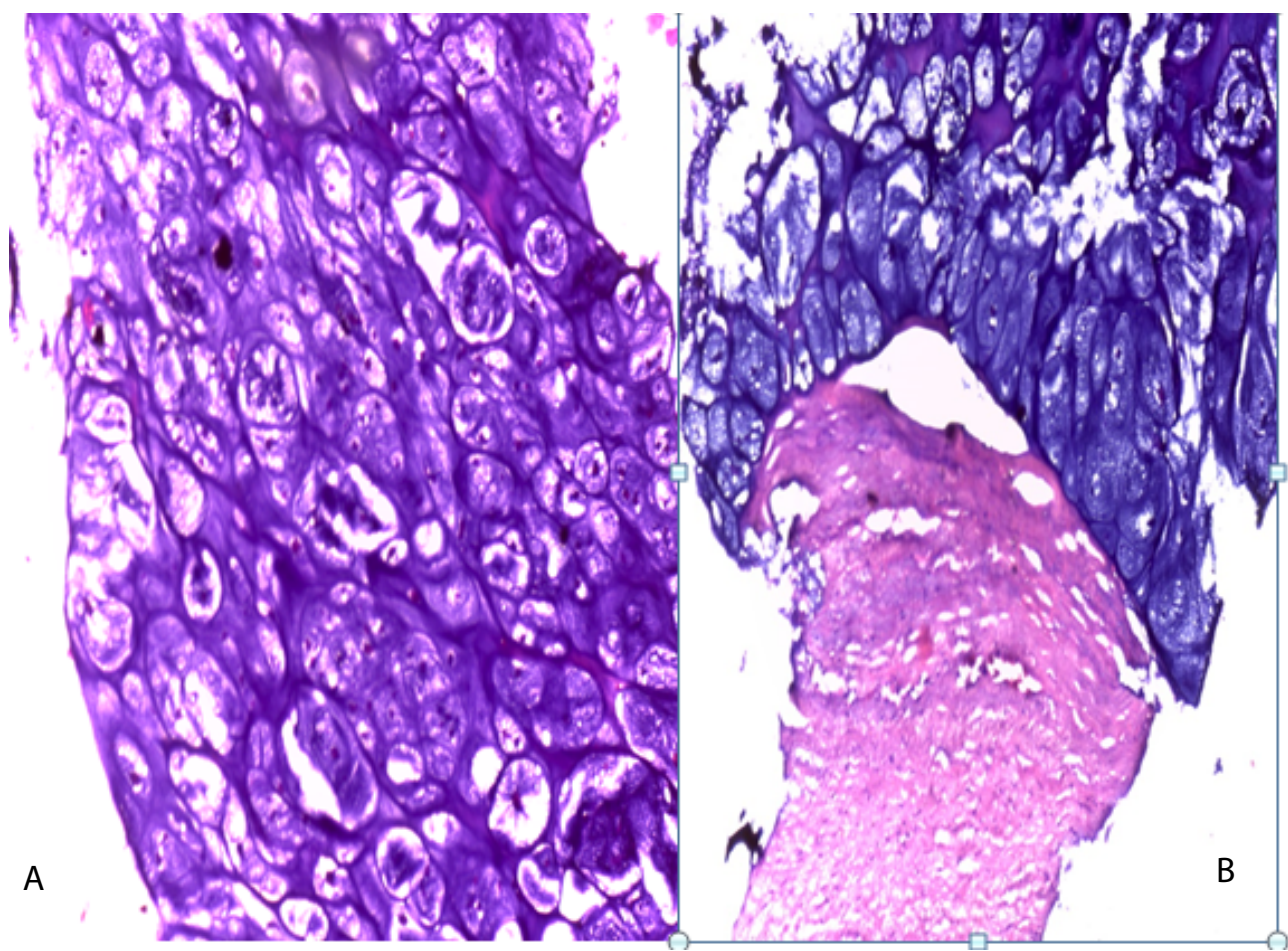

Coloration : hematoxylin and eosin; Magnification (A : X400; B : X100)

Figure 3. Histological image showing a malignant sarcomatous tumour proliferation consisting of many atypical chondrocytes with hyperchromatic nuclei and mitoses in small quantities. They are arranged in layers within a fibrous stroma.

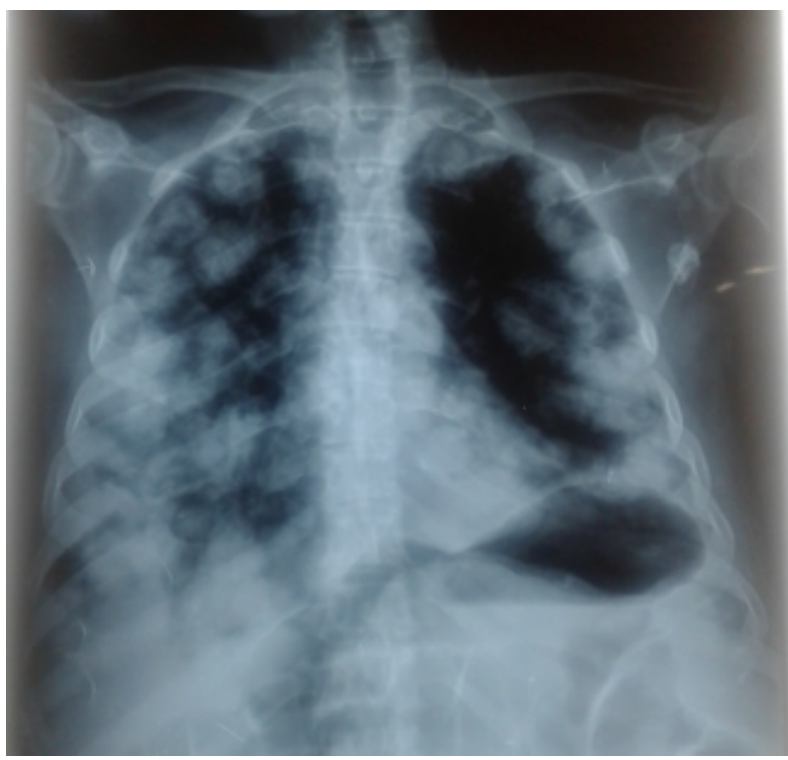

Figure 4. Thoracic radiography showing pulmonary metastasis (diffuse images in the form of balloon releases dispersed to both pulmonary fields).

MED which is a rare disease ${ }^{12}$. Our observation is the first Senegalese case report.

In more than $90 \%$ of cases, it is the cartilage cap that degenerates, giving a chondrosarcoma ${ }^{8,17}$, as in our patient. In the remaining cases, malignant transformation occurs in the stem of the exostosis as osteosarcoma or sarcoma of fusiform cells ${ }^{8,17,18}$. It can occur at any age, however, according to our observation, it is more frequent around 30 years of age, with an increased risk with age ${ }^{8}$. In the study by Czajka C.M et al, the age ranged from 19 to 48 years $^{11}$. 
It is important to pay attention to the predictive factors of malignant degeneration in any patient followed for $\mathrm{MED}^{2}$ for a preventive approach. In a study including 529 patients in 2011, Pedrini, et al showed that the risk of malignant transformation of exostosis was correlated with their location in the pelvic girdle (pelvic region, proximal hip) and scapular girdle (scapula) ${ }^{19}$. In the study by Czajka M.C et al, the site most frequently concerned was the pelvic region (8 cases out of 21 cases), followed by the scapula (4 cases 21 cases $)^{11}$. According to some authors, this association could be linked to delayed detection of osteochondromas in these zones as a result of the least compressive complications of exostosis $^{8}$. Other risk factors for malignant degeneration reported in the literature were: genetic predisposition (especially EXT1 mutation), male sex, number of exostosis, reactivation of exostosis activity after the stop of growth ${ }^{2,19}$. All these factors were found in our patient, with the exception of genetic predisposition, which has not been explored. The reactivation of activity of exostosis was characterized in our patient by the occurrence of pain of iliac exostosis which increased in volume ${ }^{2,19}$. The technical platform did not allow genetic tests to be carried out ; which is a limitation in this study. However, the multiple forms of exostosis and the existence of the disease in a first-degree relative suggests a genetic predisposition in our patient ${ }^{2}$. Thus, a family history of the disease would be described in $60 \%$ of cases $^{2}$.

In the study by Czajka C.M et al, the exostosis that recurred after surgical treatment were all localized to the pelvic girdle (pelvis and upper end of the femur) and the scapular girdle (scapula and sternum) ${ }^{11}$. Surgical removal indicated for any active exostosis, as was the case with our patient, remains the primary treatment for osteochondromas ${ }^{2,20,21}$. However, it is a symptomatic treatment ${ }^{2,20}$. However, it is a symptomatic treatment and is often repeated in patients with $\mathrm{MED}^{2,11}$.

On the prognostic level, malignant degeneration represents the most serious complication of exostosis. It may be responsible for death as was the case with our patient $^{2,13}$. In the Egyptian study, the mortality rate was $20 \%$ in the group of solitary exostosis and $44 \%$ in the group of multiple exostosis disease ${ }^{13}$.

\section{Conclusion}

Themalignantdegeneration of multiple exostosis disease is rarely described in African literature. Our observation is the first Senegalese case report. The occurrence of death in our patient suggests regular monitoring of MED. This allows early detection and management of risk factors for malignant degeneration.

\section{References}

1. Solomon L. Hereditary multiple exostosis. Am J Hum Genet. 1964; 16 351 .
2. Robin F, Ropars M, Violas P, et al. Multiples Hereditary multiple. Rev Rhum monographies. 2019; 86: 84-91.

3. Yang A, Kim J, Ja-Hyun Jang JH, et al. Identification of a novel mutation in EXT2 in a fourth-generation Korean family with multiple osteochondromas and overview of mutation spectrum. Ann Hum Genet. 2019; 83: 160-170.

4. Cook A, Raskind W, Blanton SH, et al. Genetic heterogeneity in families with hereditary multiple exostoses. Am J Hum Genet. 1993; 53: 71-79.

5. Sfar S, Abid A, Mahfoudh W, et al. Genetic analysis of hereditary multiple exostoses in Tunisian families: a novel frame-shift mutation in the EXT1 gene. Molecular Biology Reports. 2009; 36 (4): 661-667.

6. Wuyts W, Van Hul W. Molecular basis of multiple exostoses: mutations in theEXT1 and EXT2 genes. Hum Mutat. 2000; 15: 220-227.

7. Rambeloarisoa J, El Guedja M, Legeai-Malletd L, et al. Hereditary multiple exostoses with 40 years follow-up: case report. Rev Med Interne. 2002; 23: 657-664.

8. Sonne-Holm E, Wong C, Sonne-Holm S. Multiple cartilaginous exostoses and development of chondrosarcomas-a systematic review. Dan Med J. 2014; 61(9): A4895.

9. Deirmengian GK, Hebela NM, O'Connell M, et al. Proximal tibial osteochon-dromas in patients with fibrodysplasia ossificans progressiva. J Bone Jt Surg. 2008; 90: 366-374.

10. Niasse M, Kane BS, Condé K, et al. Multiple Exostosis Disease. J Rare Dis Res Treat. 2019; 4(2): 28-33.

11. Czajka CM, DiCaprio MR. What is the Proportion of Patients With Multiple Hereditary Exostoses Who Undergo Malignant Degeneration? Clin Orthop Relat Res. 2015; 473: 2355-2361.

12. Feia Li, Ngoh C, Portera DE. Chondrosarcoma transformation in hereditary multiple exostoses: A systematic review and clinical and cost-effectiveness of a proposed screening model. Journal of Bone Oncology. 2018; 13: 114-122.

13. Ahmed AR, Tan TS, Uni KK, et al. Secondary chondrosarcoma in osteochondroma: report of 107 patients. Clinical Orthopaedics and Related Research. 2003;411: 193-2006.

14. Chahdi H, Damiri A, Ochi MEE, et al. Chondrosarcoma arising in solitary osteochondroma: a case study. Pan Afr Med J. 2019; 32: 143.

15. Solomon L. Chondrosarcoma in Hereditary Multiple Exostosis. S Afr Med. 1974; 48: 671-676.

16. Vlok SCS, Wagener GWW, Zaharie D. Secondary chondrosarcoma: Malignant transformation of pre-existing hereditary and nonhereditary cartilaginous lesions. S Afr J Rad. 2014; 18(2).

17. Hameetman L, Taminiau A, Kroon HM, etal. Multiple osteochondromas: clinicopathological and genetic spectrum and suggestions for clinical management. Hered Cancer Clin Pract. 2004; 2: 161-173.

18. Meissner SA, Vieth V, Augustc C, et al. Radiology-pathology conference: osteosarcoma in a cartilaginous exostosis of the femur. Clinical Imaging. 2006; 30: 206-209.

19. Pedrini E, Tremosini M, Milanesi A, et al. Genotype-phenotype correlation study in 529 patients with multiple hereditary exostoses: Identification of protective and risk factors. J Bone Joint Surg. 2011; 93-A: 2292-302.

20. Nasr B, Albert B, David CH, et al. Exostoses and Vascular Complications in the Lower Limbs: Two Case Reports and Review of the Literature. Annals of Vascular Surgery. 2015; 29: 1315.e7-1315.e14.

21. Niasse M, Kane BS, Mahaman GS, et al. Multiple Exostosis Disease: Study of Three Senegalese Families. SM Musculoskelet Disord. 2019; 4(1): 1032 . 